\title{
International Journal of Information Technology, Modeling and Computing (IJITMC)
}

$$
\text { ISSN : 2320-7493 (Online) ; } 2320 \text { - } 8449 \text { (Print) }
$$

ISSN : 2320-7493 (Online)

; 2320 - 8449 (Print)

\section{IJTMC}

\section{International Journal of Information Technology, Modeling and Computing}

Academy \& Tndustry Regearch Collaboration Center (AIRCC)

https://airccse.org/journal/ijitmc/index.html 


\section{SCOPE OF THE JOURNAL}

The International Journal of Information Technology, Modeling and Computing (IJITMC) is an open access peer-reviewed journal that publishes articles which contribute new results in all areas of Information Technology, Modeling and Computing. With the advances of Information Technology, there is an active multi-disciplinary research in the areas of IT, CSE, Modeling and Simulation with numerous applications in various fields. The International Journal of Information Technology, Modeling and Computing (IJITMC) is an abstracted and indexed international journal of high quality devoted to the publication of original research papers from IT, Modeling, CSE and Control Engineering with some emphasis on all areas and subareas of computer science, IT, scientific modeling, simulation, visualization and control systems and their broad range of applications.

Topics of interest within the scope of this issue include, but are not limited to, the following areas:

- Advanced computing techniques

- Algorithm and analysis

- Automation

- Bio-informatics

- Bio-modeling and applications

- Chaos theory and control

- Compression techniques

- Computer graphics

- Computer vision

- Control applications

- Control theory

- Cryptography and applications

- Data encryption

- Data Mining

- Digital image processing

- Digital signal processing

- Evolutionary algorithms

- Filtering

- Flight control and surveillance systems

- Fuzzy logic and control

- Genetic algorithms and applications

- Guidance control systems

- Image processing

- Industrial applications

- Information networking
- Intelligent and natural computing

- Intelligent systems

- Mathematical control theory

- Modeling and visualization

- Multimedia computing

- Multimedia systems

- Networks and Computing

- Neural networks

- Nonlinear control systems

- Navigation

- Pattern recognition

- Process control and instrumentation

- Robotics and applications

- Robust control

- Secure communication

- Secure systems

- Scientific and engineering modeling

- Signal processing

- Soft computing techniques in control

- Stochastic control and filtering theory

- System Science and Engineering

- System identification and modeling

- Systems and automation

- System modeling and control

\section{https://airccse.org/journal/ijitmc/index.html}




\section{MEMBERS OF THE EDITORIAL BOARD}

\section{Editorial Board}

- Abd El-Aziz Ahmed, Anna University, India

- Alarcon Ramirez,Howard University, USA

- Amandeep Verma,Punjabi University Regional Centre Mohali, India

- Anand Nayyar, Duy Tan University, Vietnam

- Ankit Thakkar, Nirma University, India

- Chandramohan.D, Pondicherry University, India

- Debajyoti Pal, Camellia Institute of Technology, India

- Durjoy Majumder, West Bengal State University, India

- Fatih Korkmaz, Cankiri Karatekin University, Turkey

- Gagan Singla, Aryabhatta College of Engineering and Technology, India

- Isa Maleki, Islamic Azad University, Iran

- Kalavathi Alla,Vasireddy Venkatadri Institute of Technology, India

- Khaled MERIT, Systemes et technologies de l'information et de la communication Tlemcen, Alegria

- Khushboo Hemnani, Rajiv Gandhi Proudyogiki Vishwavidyalaya, India

- Kishore Ghosh,West Bengal University of Technology, India

- Krishna Prasad P.E.S.N, Prasad V. Potluri Siddhartha Institute of Technology, India

- Leila Yousefi, Azad university of Qazvin, Iran

- Lokeswara Reddy V, K.S.R.M College of Engineering, India

- Long Cheng, Kiwii Power Technology Corporation, USA

- Malleswaran M,Anna University Tirunelveli, India

- Mansaf Alam, Jamia Millia Islamia - New Delhi, India

- Manu Sood, Himachal Pradesh University, India

- Meena Sharma, Institute of Engineering and Technology, DAVV, India

- Munivara Prasad K, Jawaharlal Nehru Technological University - Hyderabad, India

- Natarajan Meghanathan, Jackson State University, India

- Nilanjan Dey, JIS College of Engineering, India

- Rahul Johari, Guru Gobind Singh Indraprastha University, India

- Rajeev G Vishwakarma, Shri Vaishanv Institute of Technology and Science - Indore, India

- Randle Olwuarotimi A,Tshwane University Of Technology, South Africa 
- Ritu Sharma, Himachal Pradesh University Shimla, India

- Saba Khalid, Integral University, India

- Salini P, Pondicherry Engineering College, India

- Sandhya M, B.S.Abdur Rahman University, India

- Sangram Ray, Indian School of Mines, India

- Sanjoy Das, Galgotias university, India

- Saravanaguru, Vellore Institute of Technology University, India

- Selvi S, R.M.K. Engineering College, India

- Shantha Kumari K, Pondicherry University, India

- Shanthi V, St.Joseph's College of Engineering Chennai, India

- Soubhik Chakraborty, Birla Institute of Technology, India

- Tara Saikumar, CMR Technical Campus Hyderabad, India

- Trisiladevi C. Nagavi, S.J. College of Engg. Mysore, India

- Usha G, Anna University Chennai,India

- Vedula Venkateswara Rao, Sri Vasavi Engineering College, India

- Vuda sreenivasarao, Bahir Dar University, Ethipoia

- Wahiba Ben Abdessalem Karaa, Higher Institute of Management of Tunis, Tunisia 


\section{PAPER SUBMISSION \& MANUSCRIPT PREPARATION GUIDE}

Authors are invited to submit papers for this journal through Email: iiitmc@aircconline.com . Submissions must be original and should not have been published previously or be under consideration for publication while being evaluated for this Journal. For paper format download the template in this page.

\section{Review Process}

Submissions are accepted for review with the understanding that the same work has been neither submitted to, nor published in, another publication. Simultaneous submission to other publications will result in immediate rejection of the paper. Papers are not within the journal scope will be rejected immediately after the pre review process.

All manuscripts will be subject to a well established, fair, unbiased peer review and refereeing procedure, and are considered on the basis of their significance, novelty and usefulness to the Journals readership. The reviewing structure will always ensure the anonymity of the referees \& it will be reviewed by 3 experts in the field. The review output will be one of the following decisions:
1. Accept
2. Accept with minor changes
3. Weak Accept with major changes
4. Reject

The review process may take approximately two three months to be completed. The Editor reserves the right to reject a paper if it does not meet the aims and scope of the journal, it is not revised well.

\section{Copy Right form}

After submitting final manuscript, you can get copy right form from AIRCC secretary

\section{Special Issue Proposal}

IJITMC invite proposals for special issues on topics that fall within the scope of this journal.

Please emailyour proposal ijitmc@aircconline.com

\section{Contact Us}

Here's where you can reach us : ijitmcjournal@yahoo.com or ijitmc@aircconline.com 


\section{Indexing}

Abstracting \& Indexing Services:

The Ariticles of IJITMC are Indexed / Abstracted in the following index services :

\section{Google}

ULRICHSWEB

GLOBAL SERIALS DIRECTORY

\section{getCITED}

\section{Citeseer}

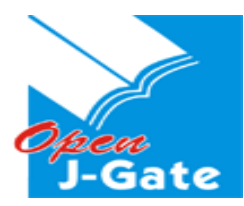

中国知识基础设施工程
(2)
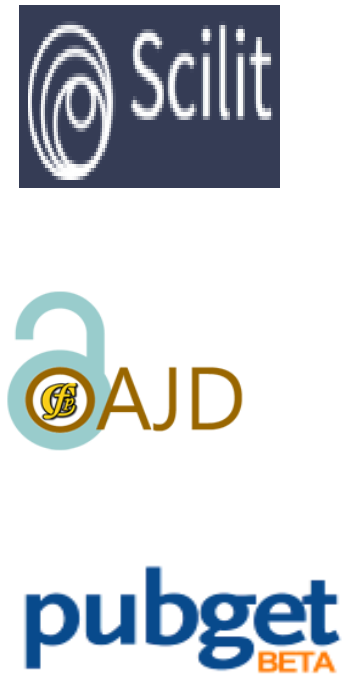

docstoc

\section{Scribd.}

\section{Bibliographic Information}

ISSN : $2320-8449$

e-ISSN : 2320 - 7493

doi : $10.5121 /$ ijitmc 


\section{Google Scholar Indexing \\ H -Index - 08, Citations 255, i10-Index 08 \\ more details}

https://scholar.google.com/citations?hl=en \&user=h2B-qnQAAAAJ

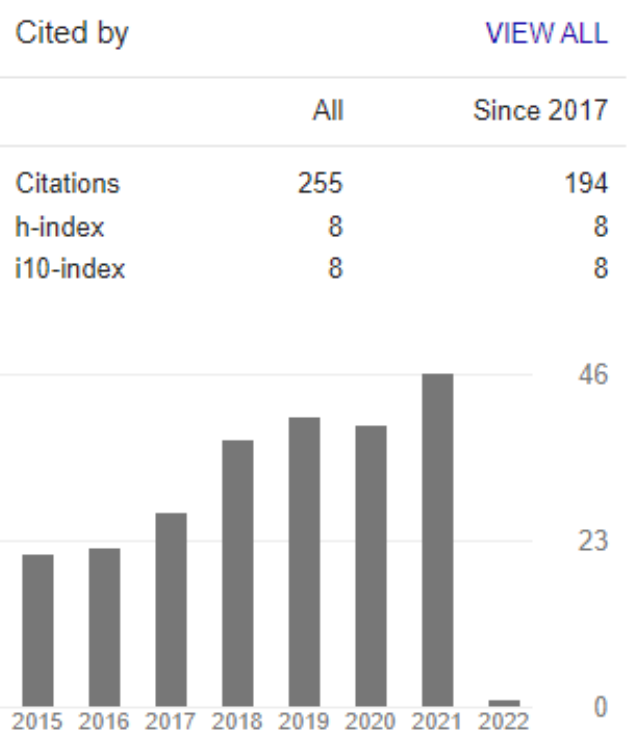

